Gut, 1975, 16, 884-886

\title{
Importance of the site of endoscopic gastric biopsy in ulcerating lesions of the stomach ${ }^{1}$
}

\author{
A. R. W. HATfield, G. SlaVin, A. W. SEgAL, AND A. J. LEVi \\ From Northwick Park Hospital and Clinical Research Centre, Harrow, Middlesex
}

SUMMARY Twenty freshly resected stomach specimens, each containing an ulcerated carcinoma, were studied in an attempt to determine the best site for gastric biopsy. Using endoscopic biopsy forceps multiple biopsies were obtained from various sites around the ulcer. Carcinoma was detected with similar frequency in biopsies from the slough and from the rim of the ulcer. The positive biopsy rate was increased to $95 \%$ when the results from the rim and the slough were combined. It is suggested that the diagnostic accuracy of endoscopic gastric biopsy can be improved by taking biopsies from both the rim and the slough of an ulcer.

Since the introduction of the newer fibrescopes, endoscopic gastric biopsy under direct vision has been widely used in the diagnosis of gastric carcinoma. Japanese authors have reported positive biopsy results in well over $90 \%$ of cas (Kasugai, 1970; Yamakawa et al., 1971) (Table 1). The fact that other authors had been unable to match these excellent results (Gear et al., 1969; Kobayashi et al., 1970; Hermanek, 1973), and that our own positive biopsy rate of $70 \%$ (Segal et al., 1975), was disappointing, prompted a study of false negative results.

\begin{tabular}{ll}
\hline Authors and Year & $\begin{array}{l}\text { Positive gastric Biopsy } \\
\text { Diagnosis (\%) }\end{array}$ \\
\hline Kasugai (1970) & 96 \\
Yamakawa et al. (1971) & 94 \\
Kobayashi et al. (1970) & 88 \\
Hermanek (1973) & 75 \\
Segal et al. (1975) & 70 \\
Gear et al. (1969) & 50 \\
\hline
\end{tabular}

Table 1 Accuracy of gastric biopsy under direct vision

There are many factors that influence the accuracy of endoscopic gastric biopsy. In particular, the

\footnotetext{
'Based on a paper presented to the British Society of Digestive Endoscopy in Birmingham, September 1974.

Address for correspondence: Northwick Park Hospital, Watford Road, Harrow, Middlesex HA1 3UJ.

Received for publication 6 August 1975
}

number of biopsies taken from each lesion and the number of sections taken from each biopsy specimen are important. The precise site of endoscopic gastric biopsy may be of considerable importance in influencing the frequency of positive results. The following study was undertaken to determine the best site for gastric biopsy in ulcerating lesions of the stomach.

\section{Methods}

Twenty freshly resected stomachs containing an ulcerated carcinoma were opened and examined. Multiple biopsies were taken under direct vision, using standard Olympus GIF-D biopsy forceps, from the carcinoma and its adjacent mucosa. Tissue was obtained from each quadrant at five standard sites as shown in Fig. 1. Each biopsy specimen was sectioned at six levels and examined by a single pathologist without knowledge of their site of origin.

\section{Results}

The biopsy findings in the 20 resected stomachs are shown in Table 2. Carcinoma was found in relatively few of the biopsies from the outer three areas, but positive biopsies were obtained with almost equal frequency in tissue from the rim and from the slough: 16 out of 20 cases $(80 \%)$ from the rim and 15 out of 20 cases $(75 \%)$ from the slough. In three cases, biopsies from the slough were positive when those from the rim were negative. The combined results of biopsies from rim and slough were positive in 19 out of 20 cases $(95 \%)$. 

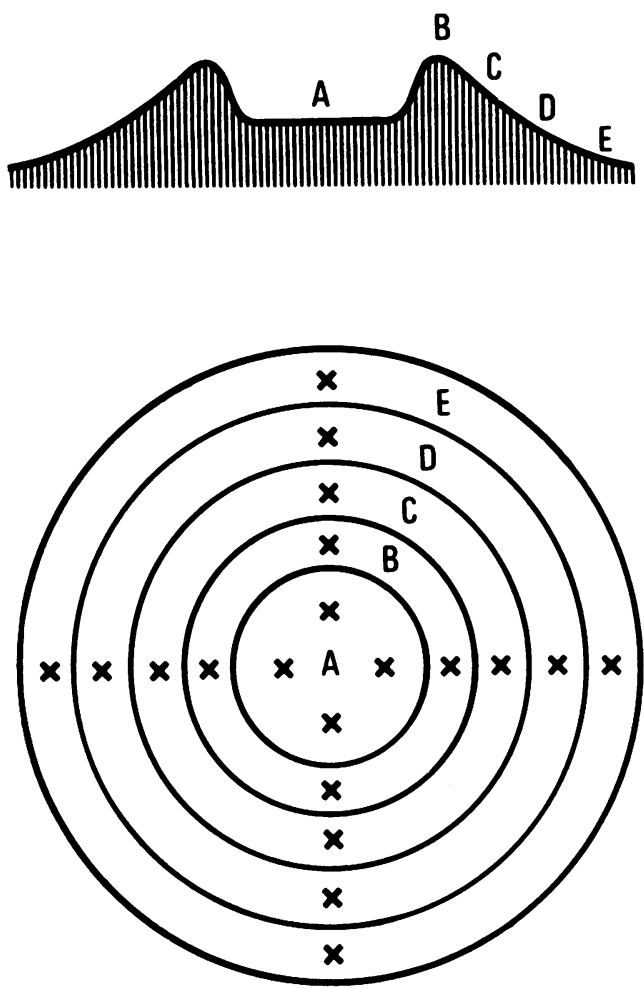

\begin{tabular}{llllll}
\hline Site & $\begin{array}{l}\text { 1 cm out } \\
\text { from base } \\
\text { of slope }\end{array}$ & $\begin{array}{l}\text { Base of } \\
\text { slope }\end{array}$ & $\begin{array}{l}\text { Half way } \\
\text { down slope }\end{array}$ & Rim & Slough \\
\hline 1 & - & - & - & + & + \\
2 & - & Atypia & - & + & + \\
3 & + & - & - & + & + \\
4 & Atypia & - & + & + & + \\
5 & - & Atypia & Atypia & + & + \\
6 & - & - & - & + & + \\
7 & Atypia & + & - & + & + \\
8 & - & - & - & + & + \\
9 & + & + & + & + & + \\
10 & - & + & + & + & + \\
11 & - & + & + & + & + \\
12 & - & - & - & + & + \\
13 & - & - & + & Atypia & - \\
14 & - & - & + & + & - \\
15 & - & - & + & + & - \\
16 & + & + & + & + & - \\
17 & - & - & - & + & - \\
18 & - & - & - & - & + \\
19 & - & - & - & - & + \\
20 & - & - & - & - & + \\
Total & $3(15 \%)$ & $5(25 \%)$ & $8(40 \%)$ & $16(80 \%)$ & $15(75 \%)$ \\
& & & Rim and & 19 out of $20(95 \%)$ \\
& & & slough & & \\
& & & combined &
\end{tabular}

Table 2 Biopsy results

+ Carcinoma present in biopsies

- No carcinoma found in biopsies

Fig. 1 Sites of biopsy. A: slough. B: rim. C: half way down slope. D: Base of slope. $E$ : $1 \mathrm{~cm}$ out from base of slope.

\section{Discussion}

Neoplastic cells may not cover the surface of the whole lesion, particularly in ulcerating tumours, and multiple biopsies increase the possibility of obtaining neoplastic tissue. Four-quadrant biopsy has been widely practised in Great Britain, but German and Japanese authors have commented on the need for a greater number of biopsies from each lesion (Ishioka et al., 1970; Kobayashi et al., 1970). In Great Britain the endoscopist with limited time and facilities might find it difficult to take more than six to eight biopsies from each lesion.

It is important that sufficient sections are cut from each biopsy specimen. If too few sections are taken, an area containing carcinoma can easily be missed. It has been advocated that up to $\mathbf{3 0}$ levels should be routinely cut from each specimen (Ackerman, 1970). This number of sections from multiple biopsies would provide more material than would be practical to examine in a busy diagnostic laboratory.

There have been many suggestions as to the best site to biopsy ulcerating lesions of the stomach. Kasugai et al. (1968) and Hermanek (1973) have recommended biopsy from the rim of an ulcer. Weiss et al. (1970) have stated that biopsy from the ulcer crater should be avoided as this usually demonstrates exudate only and lacks tissue structure. The results from this present study show that biopsies from the slough were almost as successful in detecting carcinoma as those from the rim. Moreover, in some cases carcinoma was detected more readily in biopsies from the slough of an ulcer crater than the rim. At this point normal mucosa may be heaped up over the subjacent neoplastic tissue which is then inaccessible to endoscopic biopsy (Fig. 2). It may well be that the development of the spiked biopsy forceps that take a larger bite will enable the deeper layers of the lamina propria at the ulcer rim to be biopsied and obtain a greater frequency of positive material. In order to improve the rate of positive gastric biopsies, a large number of biopsies from each lesion and numerous sections from each biopsy specimen are desirable but each is limited by practical considerations. However, this study suggests that the diagnostic accuracy of endoscopic gastric biopsy in ulcerating lesions of the stomach can be improved with a limited number of biopsies by obtaining tissue from both the rim and the slough of an ulcer. 


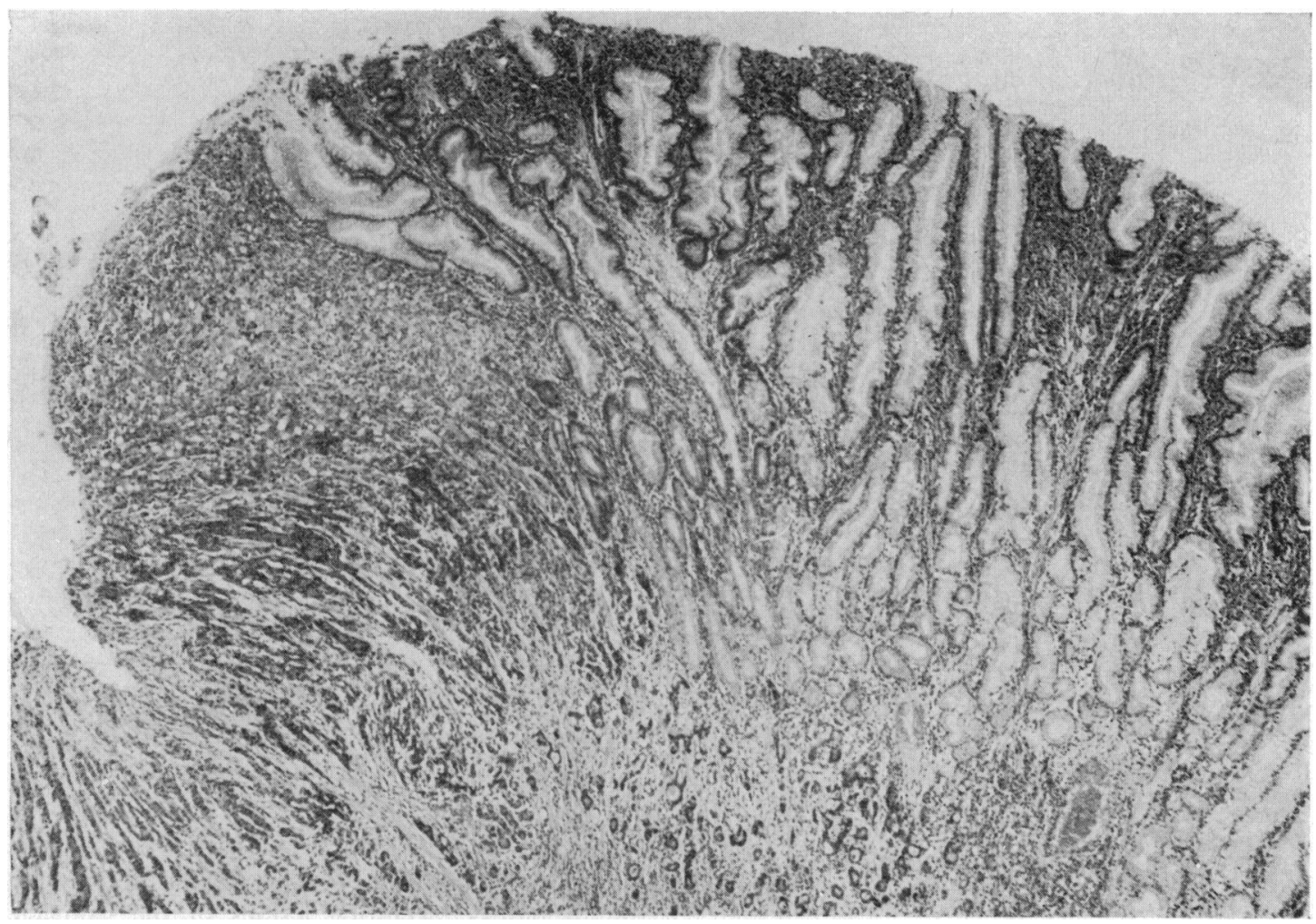

Fig. 2 At the rim of the ulcer, carcinoma is present in the submucosa and the deeper portion of the lamina propria, but not in the superficial mucosa. Neoplastic cells can be seen at the surface in the ulcer slough. Mucosal biopsies from the ulcer rim in this particular case were negative. $H$. and $E ., \times 18$.

We would like to thank Mr. A. G. Cox for his cooperation in allowing us to study resected stomach specimens.

\section{References}

Ackerman, L. V., and Del Regato, J. A. (1970). Cancer:Diagnosis, Treatment, and Prognosis. 4th edn. Mosby: St. Louis.

Gear, M. W. L., Truelove, S. C., Williams, D. G., Massarella, G. R., and Boddington, M. M. (1969). Gastric cancer simulating benign gastric ulcer. British Journal of Surgery, 56, 739-742.

Hermanek, P. (1973). Gastrobiopsy in cancer of the stomach. Endoscopy, 5, 144-147.

Ishioka, K., Ueno, K., and Yamagata, S. (1970). Direct vision biopsy and cytological diagnosis. Stomach Intestine (Tokyo). 5, 829-836.

Kasugai, T. (1970). Prognosis of early gastric cancer.
Gastroenterology, 58, 429-431.

Kasugai, T., Ito, E., and Tsubouchi, M. (1968). Gastric biopsy under direct vision. Stomach Intestine (Tokyo), 3, 1211-1226.

Kobayashi, S., Prolla, J. C., Winans, C. S., and Kirsner, J. B. (1970). Improved endoscopic diagnosis of gastroesophageal malignancy. Journal of the American Medical Association, 212, 2086-2089.

Segal, A. W., Healey, M. J. R., Cox, A. G., Williams, I., Slavin, G., Smithies, A., and Levi, A. J. (1975). Diagnosis of gastric cancer. British Medical Journal, 2, 669-672.

Weiss, J., Gang, M., Ekkers, T., Gaetz, H., and McCray, R. (1970). Direct vision gastric biopsy using the Machida FGS-B6 gastroscope. Gastrointestinal Endoscopy, 1, 23-27.

Yamakawa, T., Panish, J., and Berci, G. (1971). The correlation of target biopsy and contact smear cytology under direct visual control in malignant gastric lesions. Gastrointestinal Endoscopy, 17, 164-168. 